\title{
Influence of Climatic Conditions on the Time Series Fluctuation of Yellowfin Tuna Thunnus albacares in the South Pacific Ocean
}

\author{
Ashneel Ajay Singh ${ }^{1,2}$, Naoki Suzuki', Kazumi Sakuramoto ${ }^{{ }^{*}}$ \\ ${ }^{1}$ Department of Ocean Science and Technology, Tokyo University of Marine Science and Technology, Tokyo, \\ Japan \\ ${ }^{2}$ Department of Fisheries, College of Agriculture, Fisheries and Forestry, Fiji National University, Nasinu, Fiji \\ Email: sakurak@kaiyodai.ac.jp
}

Received 7 April 2015; accepted 31 May 2015; published 3 June 2015

Copyright $(2015$ by authors and Scientific Research Publishing Inc.

This work is licensed under the Creative Commons Attribution International License (CC BY). http://creativecommons.org/licenses/by/4.0/

(c) (i) Open Access

\section{Abstract}

Yellowfin tuna (Thunnus albacares) is one of the most commercially important fish species for South Pacific island nations and territories and for effective conservation efforts it is important to understand the factors which affect its time series pattern. Our research was aimed at elucidating the climatic factors which affected the trajectory of the yellowfin tuna stock in the Eastern and Western South Pacific Ocean. We utilized various climatic factors for the years $t-n$ with $n=0,1, \cdots$, 8 and investigated their statistical relationship with the catch per unit effort (CPUE) of yellowfin tuna stock from 1957-2008 for three South Pacific zones ranging from the East to the West Pacific Ocean within the coverage area of the Western and Central Pacific Convention Area. Results showed that the climatic conditions of: (i) the global mean land and ocean temperature index (LOTI), (ii) the Pacific warm pool index (PWI) and (iii) Southern Oscillation Index (SOI) had significant relationship with the CPUE of yellowfin tuna in all three zones. LOTI, PWI and SOI were used as independent variables and fitted through modeling to replicate the CPUE trajectory of the yellowfin tuna in Zone 1, Zone 2 and Zone 3. Model selection was based on significant parameter estimates $(p<0.05)$, Akaikes Information Criterion (AIC) and $R^{2}$ values. Models selected for all three zones had LOTI, PWI and SOI as the independent variables. This study shows that LOTI, PWI and SOI are climatic conditions which have significant impact on the fluctuation pattern of the yellowfin tuna CPUE in the Eastern and Western South Pacific Ocean. From the findings of this study it can be recommended that when management decisions are made for yellowfin tuna fishery conservation and sustainability in the Eastern and Western South Pacific, it is imperative to take the effect of climatic factors into account.

\footnotetext{
*Corresponding author.
} 


\section{Keywords}

\section{Yellowfin Tuna, Global Mean Land and Ocean Temperature Index, Pacific Warm Pool Index, Southern Oscillation Index, Thunnus albacares}

\section{Introduction}

Yellowfin tuna (Thunnus albacares) is one of the highly migratory species of tuna which has been of significant commercial importance to the nations that fall within the Western and Central Pacific Convention Area (WCPCA) including the South Pacific Island countries and territories where yellowfin tuna forms one of the major revenue contributors for the fisheries sector [1]-[6]. As a migratory species, yellowfin tuna has a median displacement of 337 - 380 nautical miles and a large proportion of the population moves beyond the exclusive economic zone (EEZ) of most countries [2] [7]. However, estimates of half-life show that the residence period of yellowfin tuna within the EEZ of Pacific Island states is approximately 6 months and due to their high growth rates, this period is sufficient to cause substantial production of the species within a single EEZ [2]. After skipjack tuna (Katsuwonus pelamis), yellowfin tuna accounts for the second highest catch in the Western and Central Pacific Ocean (WCPO). The global demand for tuna has been increasing and effort levels for tuna harvests in the WCPCA have been intensifying as other oceanic areas are becoming overharvested [8]. This exposes the Pacific tuna species to greater fishing pressure and increases vulnerability of the declining of stock levels beyond sustainability limits. However, the stock assessment of tuna species is complicated as alternations in climatic conditions also affect their stock dynamics.

El Niño-Southern Oscillation (ENSO) and El Niño and La Niña events have been observed to affect the stock distribution and abundance of tuna species by altering primary productivity of oceanic areas [9] [10]. Significant impact of various climatic conditions has been documented over the years for different commercially important tuna stocks. Changes in the climatic conditions of the North Atlantic Oscillation (NAO) and Northern Hemisphere Temperature anomaly have caused significant changes in the migration and spatial distribution of the North Atlantic albacore (Thunnus alalunga) and Eastern Atlantic bluefin (Thunnus thynnus) tuna over a period of 40 and 25 years respectively in the Northeast Atlantic Ocean [11]. In the Pacific Ocean, Lehodey [12] showed that positive Pacific Decadal Oscillation (PDO) and El Niño events frequency were favorable for the recruitment of yellowfin and skipjack tuna while albacore tuna recruitment was enhanced by negative PDO and La Niña events. During El Niño events which are followed by La Niña events, catches of skipjack tuna has been observed to be high in the Pacific region where the Warm Pool and the Pacific Equatorial Divergence converge. The Southern Oscillation Index (SOI) which is related to El Niño and La Niña events has also been shown to be related to skipjack tuna stock and yellowfin tuna catch time series [8] [9] [13]-[15].

The fluctuation patterns of fish are complex and result from the interaction of various intrinsic and extrinsic factors working together. It is important to understand the role of climatic conditions in the stock dynamics of commercially important fish species and make the information available to fishery decision makers as the significance of climatic factors in fisheries stock abundance and distribution cannot be ignored. The aim of this study is to explore the relationships of climatic conditions with the stock trajectory of yellowfin tuna (T. albacares) in the South Pacific region. Environmental factors are used as independent variables and suitable stock reproduction models are developed to explain the fluctuation pattern of the yellowfin tuna time series.

\section{Materials and Methods}

\subsection{Data}

Catch and effort data for the yellowfin tuna (T. albacares) in the Eastern and Western South Pacific region from 1957 to 2008 was obtained from the Western and Central Pacific Fisheries Commission (WCPFC) public domain data (https://www.wcpfc.int/) aggregated in $5^{\circ}$ by $5^{\circ}$ spatial grids. The stock distribution of the yellowfin tuna selected for this study is shown in Figure 1.

Only the longline data for yellowfin tuna was utilized for this study as it was the most extensive with reference the time series range and the possibility of observation errors for the effort were much less compared to 


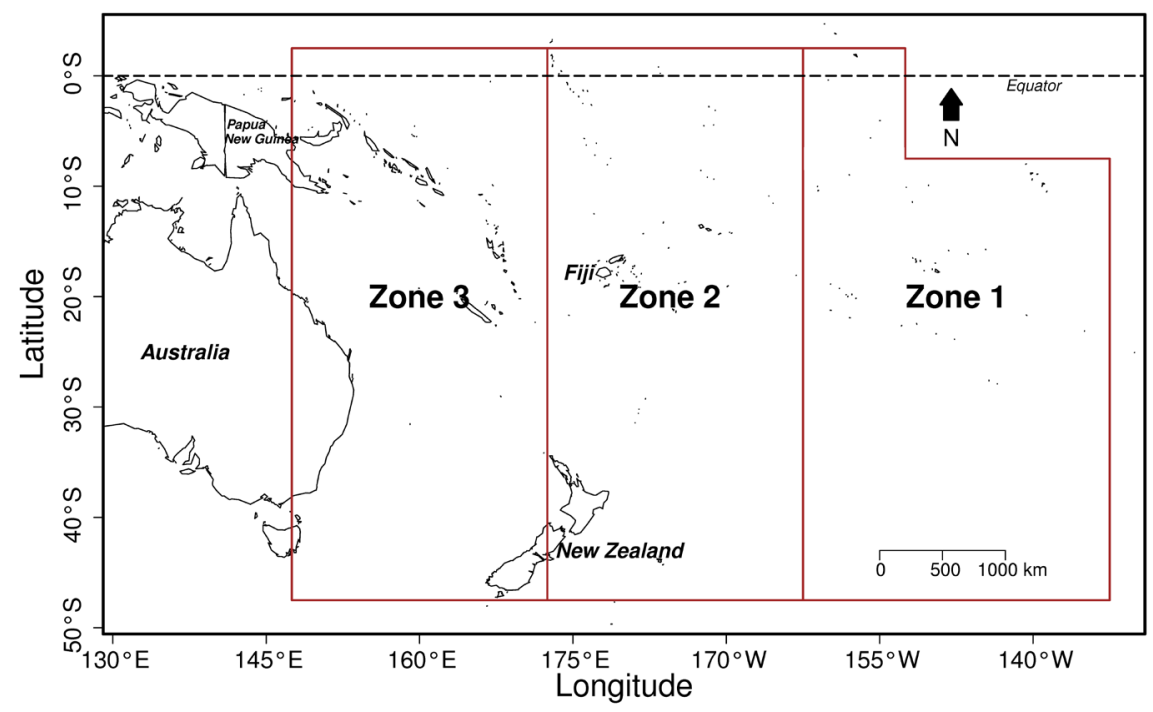

Figure 1. Map of the Eastern and Western South Pacific region showing the stock distribution of the yellowfin tuna (T. albacares). The region is divided into Zone 1, Zone 2 and Zone 3 shown by the enclosure polygons.

pole and line and purse seine data. The type of effort data for longline was by the number of hooks which was preferable over the effort data for pole and line and purse seine which was by the number of fishing days. The data for yellowfin tuna were separated into three areas; Zone $1\left(2.5^{\circ} \mathrm{N}-47.5^{\circ} \mathrm{S}, 162.5^{\circ} \mathrm{W}-152.5^{\circ} \mathrm{W}, 7.5^{\circ} \mathrm{S}-\right.$ $\left.47.5^{\circ} \mathrm{S}, 152.5^{\circ} \mathrm{W}-132.5^{\circ} \mathrm{W}\right)$, Zone $2\left(2.5^{\circ} \mathrm{N}-47.5^{\circ} \mathrm{S}, 172.5^{\circ} \mathrm{E}-162.5^{\circ} \mathrm{W}\right)$ and Zone $3\left(2.5^{\circ} \mathrm{N}-47.5^{\circ} \mathrm{S}, 147.5^{\circ} \mathrm{E}-\right.$ $172.5^{\circ} \mathrm{E}$ ) (Figure 1) by geolocating and isolating the latitude and longitude coordinates which fell within each zone. Annual catch and effort for the yellowfin tuna in Zone 1, 2 and 3 were calculated from aggregated longline monthly data by latitude and longitude coordinates. From the catch and effort data, the catch per unit effort (CPUE) for Zone 1, Zone 2 and Zone 3 were calculated (Figures 2(a)-(c)). For CPUE calculation, the catch data used was in tonnes and effort was the number of hooks used. Exploratory analysis showed differences in the CPUE, catch magnitude and catch and effort relationship for yellowfin tuna time series in the three zones which made it essential to treat Zone 1, Zone 2 and Zone 3 as three different stocks.

The CPUE time series fluctuation pattern for the yellowfin tuna in Zone 1 can be seen in Figure 2(a) for the years 1957 to 2008. From 1960-1964, 1970-1972, 1974-1976, 1981-1983, 1984-1986, 1988-1990, 1992-1994 and 1995-1997 there is an increasing trend and for the years 1958-1960, 1964-1967, 1968-1970, 1972-1974, 1976-1978, 1979-1981, 1986-1988, 1990-1992, 1997-1999, 2000-2003 and 2006-2008 a decreasing trend can be observed with the maximum peak in 1964 and minimum in 2008. For the trajectory of yellowfin tuna in Zone 2 (Figure 2(b)) we can see an increasing trend for the years 1958-1960, 1974-1978 and 1981-1983 while a decreasing trend can be observed for the years 1963-1967, 1968-1971, 1972-1974, 1978-1981, 1985-1989, 1992-1995, 1996-1999, 2000-2003 and 2004-2006. The CPUE is at peak for the years 1960 and 1963, however from this point an overall gradual decline in the yellowfin tuna in Zone 2 can be seen until 2008 with the lowest point for the CPUE in the years 1974, 1981, 1991, 2003 and 2008. Finally for Zone 3 (Figure 2(c)) the CPUE has an increasing trend for the years 1962-1964, 1974-1978, 1986-1988 and 1993-1996 with a decreasing trend from 1957-1959, 1960-1962, 1971-1974, 1988-1991, 1996-1999 and 2002-2004. CPUE is highest in 1957, 1960 and 1964 and lowest in 1974 and 1999. The CPUE trends in Zone 2 and Zone 3 have more similarities with each other compared with Zone 1 where the CPUE fluctuates intensively between high and low peaks over the time series.

Global Mean Land and Ocean Temperature Index (LOTI) for the latitude band $0^{\circ} \mathrm{N}$ to $24^{\circ} \mathrm{S}$ from 1949 to 2008 was obtained from the National Aeronautics and Space Administration (NASA), Goddard Institute for Space studies, Goddard Space Flight Center, Science and Exploration Directorate, Earth Science Division (http://data.giss.nasa.gov/gistemp). Monthly data for the Pacific warm pool index (PWI) from 1949 to 2008 and Southern Oscillation Index (SOI) from 1951 to 2008 were obtained from the National Oceanic and Atmospheric Administration (NOAA), Earth System Research Laboratory, Physical Sciences Division (http://www.esrl.noaa.gov). 


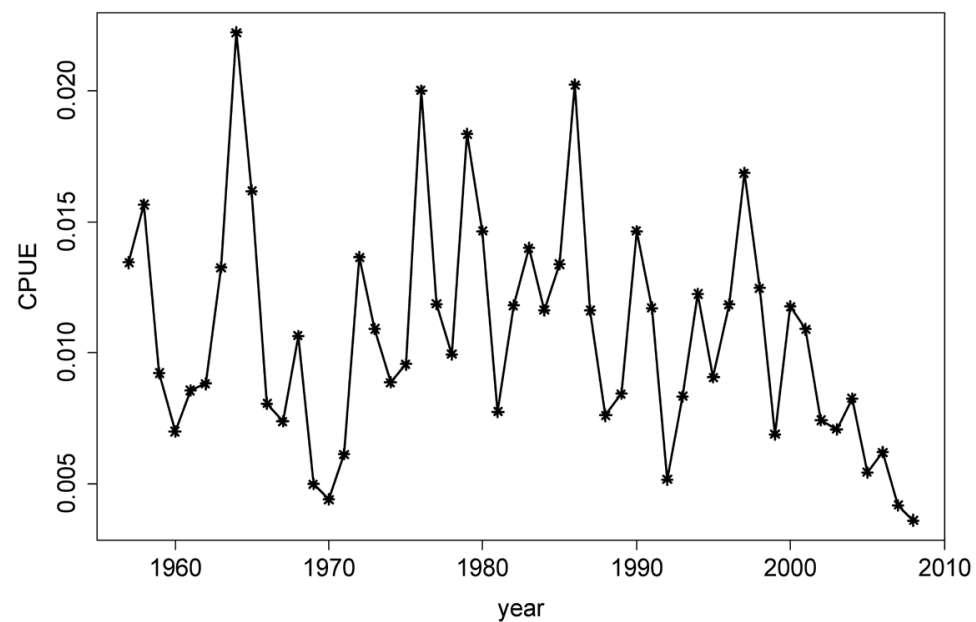

(a)

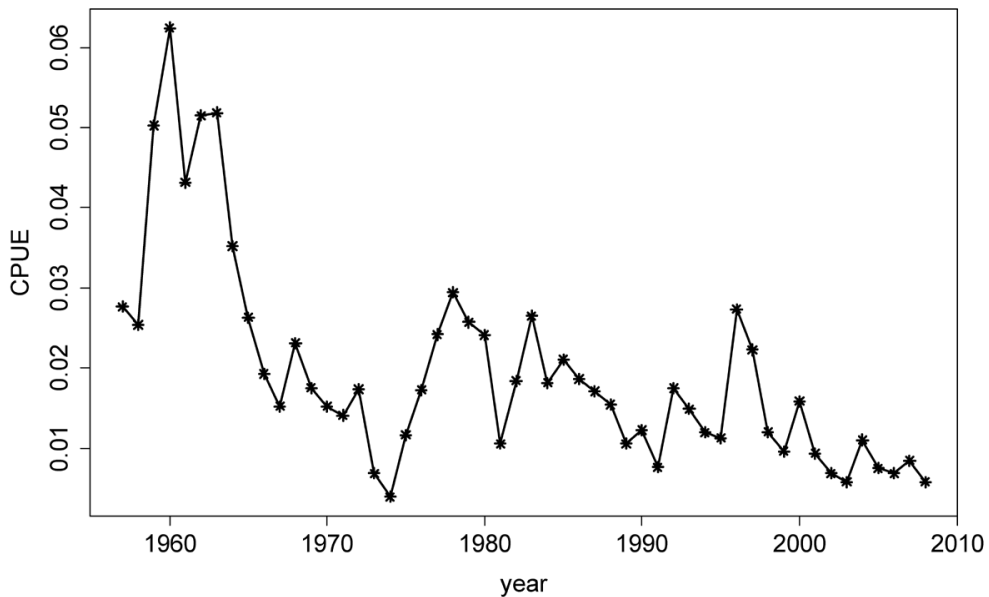

(b)

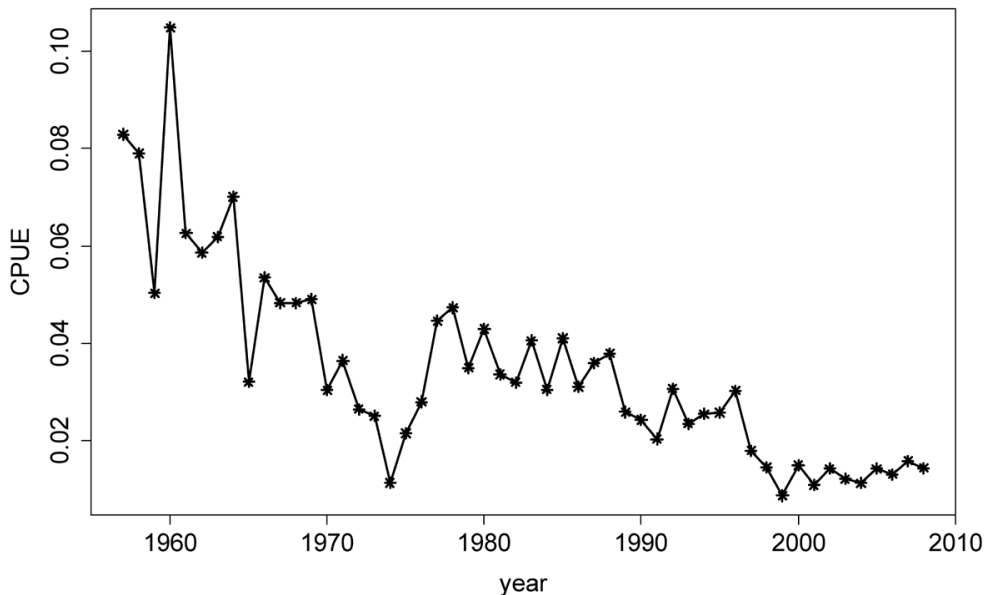

(c)

Figure 2. (a) The CPUE time series trajectory of the yellowfin tuna (T. albacares) stock in Zone 1. Time series is shown for the years ranging from 1957-2008; (b) the CPUE time series trajectory of the yellowfin tuna (T. albacares) stock in Zone 2. Time series is shown for the years ranging from 1957 to 2008; (c) the CPUE time series trajectory of the yellowfin tuna (T. albacares) stock in Zone 3. Time series is shown for the years ranging from 1957 to 2008. 


\subsection{Exploratory Analysis and Unit Root Test}

To identify if relationships existed between dependent and independent variables, we applied regression analysis of the dependent variables of yellowfin tuna CPUE in Zone $1\left(Y_{z 1}\right)$, Zone $2\left(Y_{z 2}\right)$ and Zone $3\left(Y_{z 3}\right)$ against the independent variables of LOTI $(L)$, monthly and annual PWI $(P)$ and SOI $(I) . Y_{z 1}, Y_{z 2}$ and $Y_{z 3}$ were tested against climatic conditions for year $t-n$ where $n=0,1, \cdots, 8$ as the lifespan of yellowfin tuna is around 5 to 8 years [16] [17]. Regression results with $p<0.05$ were considered as significant relationships. Dependent variables as well as independent variables which showed significant relationships to dependent variables were tested for the presence of outliers using boxplots and scatterplots and correlations among independent variables as outlined in [18]. Coefficient of correlation with $R>0.500$ was considered as significant. The protocol for data exploration was followed as outlined in [18] to avoid violations of assumptions from the statistical techniques utilized.

Time series data can have either a deterministic trend which is a stationary process or stochastic trend which is non-stationary process. When alteration or shocks in trend have transitory effects on a time series with deterministic trend the time series remains a stationary process and when these shocks causes permanent alterations to a trend the time series is categorized as having a stochastic process or a unit root. For a given time series the presence of a unit root can cause unauthentic correlations in analysis techniques such as regression analysis [19] [20]. Yellowfin tuna CPUE in Zone 1, Zone 2 and Zone 3 as well as the independent variables which exhibited significance correlation with the dependent variables were analyzed with the Augmented Dickey-Fuller and MacKinnons unit root test to confirm whether any of the time series data were a non-stationary process [19][21].

\subsection{Stock Reproduction Model}

From exploratory analysis the individual independent variables which showed significant relationship at $p<$ 0.05 with yellowfin tuna CPUE in Zone 1, Zone 2 and Zone 3 with highest $R^{2}$ and lowest AIC values were incorporated into stock reproduction models. Here, the stock reproduction model is an attempt to reconstruct the CPUE trajectory of yellowfin tuna in the three South Pacific zones by fitting climatic data as independent variables. The parent formula used for the stock reproduction model for Zone 1, Zone 2 and Zone 3 was a Generalized Linear Model (GLM) shown below

$$
\ln \left(Y_{s, t}\right)=\ln \left(\alpha_{0}\right)+\alpha_{1} x_{1, t-n}+\alpha_{2} x_{2, t-n}+\cdots+\alpha_{k} x_{k, t-n}+\varepsilon_{s, t}
$$

where $Y_{s}$ is the yellowfin tuna CPUE with $s=$ Zone 1 (z1), Zone 2 (z2) and Zone 3 (z3), $\alpha_{0}$ is the intercept parameter, $\alpha_{1}, \alpha_{2}, \cdots, \alpha_{k}$ are parameter estimates, $x_{1}, x_{2}, \cdots, x_{k}$ are the independent variables, $t$ is the year with $n=0,1$, $\cdots, 8$ and $\varepsilon_{s, t}$ is a random variable which is normally distributed and cannot be explained.

The response surface methodology (RSM) uses linear and polynomial functions to incorporate independent variables into mathematical and statistical models to describe a system or data which is under investigation [22]-[25]. Equation (1) was modified and expanded using RSM by incorporation of polynomials of the second and third order to determine if variables could be better fit with this technique (Equation (2)).

$$
\ln \left(Y_{s, t}\right)=\ln \left(\alpha_{0}\right)+\alpha_{1} x_{1, t-n}+\alpha_{2} x_{2, t-n}+\alpha_{3} x_{1, t-n}^{2}+\alpha_{4} x_{2, t-n}^{2}+\cdots+\alpha_{k} x_{k, t-n}^{m}+\varepsilon_{s, t}
$$

where $m=1,2,3$. The dependent variable and y-intercept were log transformed to reduce the effects of skewness and outliers. Various combination or the independent variables were investigated by successive elimination for the linear model and with polynomial combinations of the independent variables for Equation (1) and Equation (2) to identify suitable models for explaining the trajectory of the yellowfin tuna stock in the three zones of the South Pacific region. The residuals of the model against the fitted values were tested for homogeneity of variance. If the range of variance were $\geq 4.00$ then the least square estimators will be significantly degraded [26]. For model selection criteria, we used the Akaikes Information Criterion (AIC) and $R^{2}$ values at $p<0.05$ with condition of significant parameter estimates at $p<0.05$ [27]. The referred trajectory of the CPUE was plotted with the predicted CPUE of the yellowfin tuna in Zone 1, Zone 2 and Zone 3 and compared. All statistical analysis for this study was carried out using the statistical software " $R$ ", version 3.0.1 [28].

\section{Results}

\subsection{Catch and Effort Trajectory}

For this study only the CPUE was used for regression analysis and model development as it better represented 
the actual fluctuation pattern of the yellowfin tuna stock in the South Pacific Zone 1, Zone 2 and Zone 3 compared to the catch time series (Figure 3). From Figure 3 it can be seen that the yellowfin tuna effort shows similar fluctuation pattern with the catch in all three cases. The correlation between catch and effort of yellowfin tuna in Zone 1, 2 and 3 can be seen in Figure 4 where the points above the slopes refer mostly to the years where the catch was high at low effort and most of the points below the slopes refer to the years where catch was low and effort levels were high. Points which recline on or close to the slope line are the years where catch and effort corresponded more closely to each other. From Figure 3 and Figure 4 the effort trajectory in Zone 1 seems to better fit the catch trajectory compared to that of Zone 2 and Zone 3. The determination coefficient for Zone $1(0.745)$ is significantly higher compared to Zone 2 (0.343) and Zone $3(0.327)$. As the catch and effort are correlated for the three zones, it can be said that the catch dynamics of the yellowfin tuna in the three fishing zones are influenced by the fishing effort. Since CPUE is defined as the catch for each unit of effort it is a much better standard representative of the true trajectory of yellowfin tuna compared to the catch time series for this study.

Figure 5 shows the similarities and differences in the yellowfin tuna catch and CPUE time series magnitudes in Zone 1, Zone 2 and Zone 3. Catch levels in Zone 3 have remained significantly higher for most of the time series from 1957-2008 compared to Zone 2 and Zone 3. Catch in Zone 2 remained higher than in Zone 1 until around the mid-1980s from which point the catch in both zones remained at similar scales up to 2008. Similarly, the CPUE in Zone 3 mostly remained significantly higher than in Zone 2 and Zone 1 until around the mid-1990s
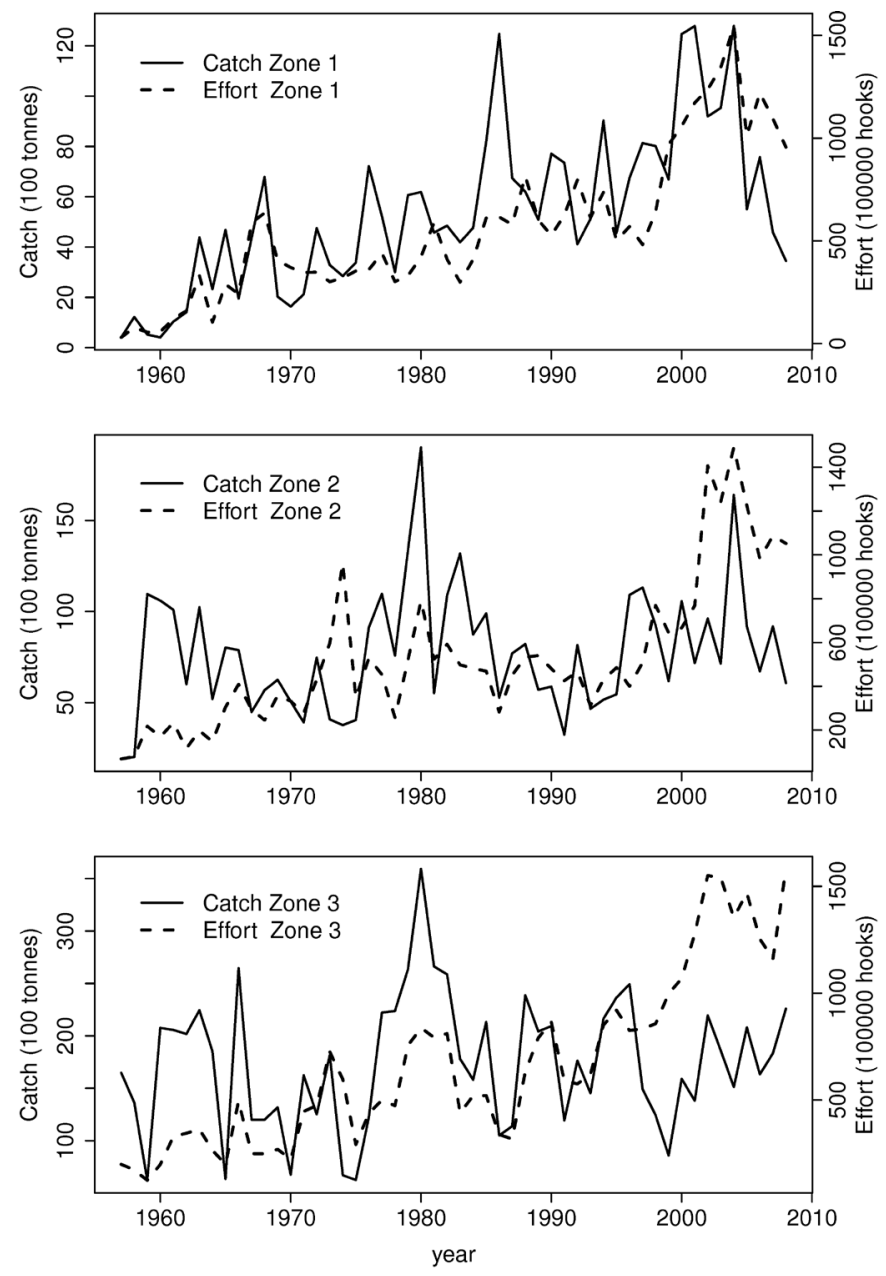

Figure 3. The catch and effort time series trajectory of the yellowfin tuna (T. albacares) stock in Zone 1, Zone 2 and Zone 3 from 1957-2008. The similarities and differences in the trajectory patterns can be observed. 

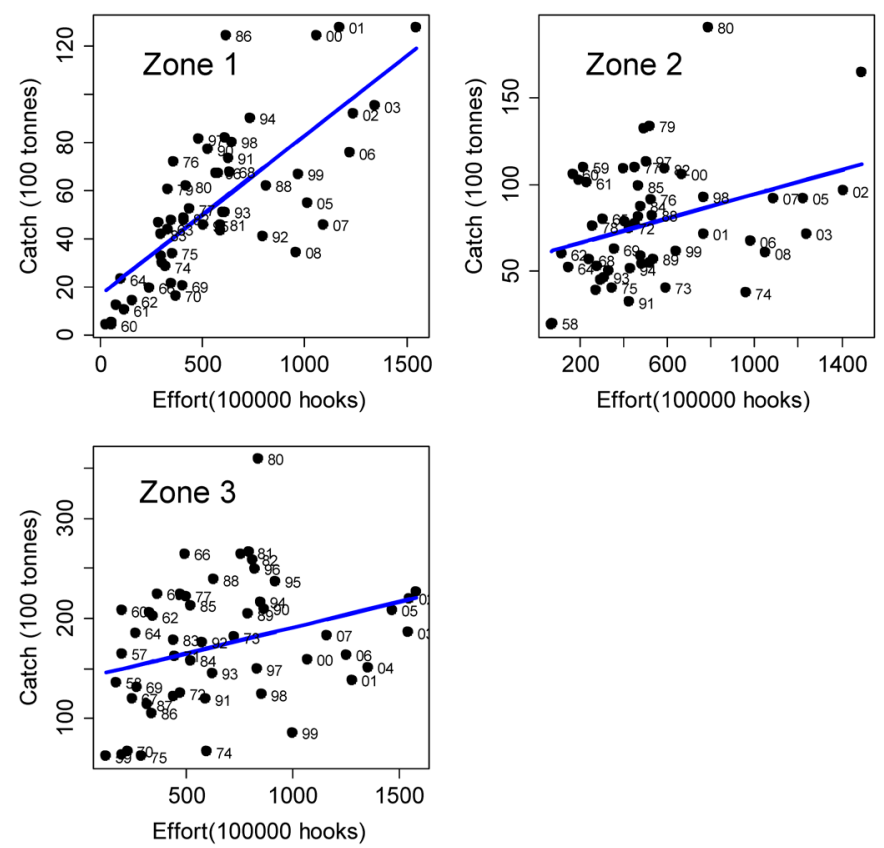

Figure 4. The relationship between the catch and effort for the yellowfin tuna ( $T$. albacares) stock in Zone 1, Zone 2 and Zone 3 from 1957-2008. The determination coefficients are $0.745,0.343$ and 0.327 respectively.
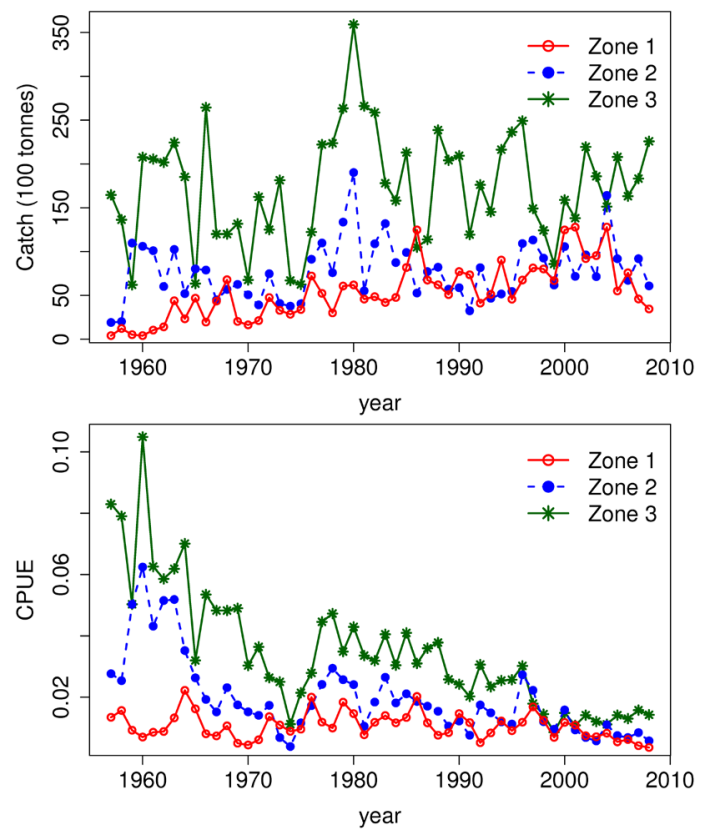

Figure 5. The catch and CPUE time series trajectory of the yellowfin tuna (T. albacares) stock in Zone 1, 2 and 3from 1957 to 2008. On average, both catch and CPUE magnitudes were highest for Zone 3 followed by Zone 2 and the smallest for Zone 1.

after which the CPUE in all three zones remained at similar levels. CPUE in Zone 2 was much higher than in Zone 1 until the early 1970s and remained more or less similar to Zone 1 from this point. On average it can be said that the stock level in Zone 3 has been the highest followed by Zone 2 and with the lowest in Zone 1 until recently where the stock levels in all three zones have been at similar levels. 


\subsection{Exploratory Analysis and Unit Root Test}

In Table 1 the results of the regression analysis of the CPUE for the yellowfin tuna in Zone 1, Zone 2 and Zone 3 of the South Pacific region against the independent climatic conditions variables for the years $t-n(n=0,1, \cdots$, 8) are shown. We have only included the variables which exhibited correlations according to the highest $R^{2}$ and

Table 1. Regression results for independent climate variables against the yellowfin tuna (T. albacares) stock in Zone 1,2 and 3. Variables exhibiting values with $p<0.05$ are regarded as significant.

\begin{tabular}{|c|c|c|c|c|c|c|c|c|c|}
\hline \multicolumn{10}{|c|}{ Zone 1} \\
\hline \multirow{2}{*}{ Year } & \multicolumn{3}{|c|}{$Y_{z 1}, L$} & \multicolumn{3}{|c|}{$Y_{z 1}, P_{s}$} & \multicolumn{3}{|c|}{$Y_{\mathrm{z} 1}, I_{a}$} \\
\hline & $R^{2}$ & $p$-value & AIC & $R^{2}$ & $p$-value & AIC & $R^{2}$ & $p$-value & AIC \\
\hline$t$ & 0.023 & $2.79 \times 10^{-1}$ & -415 & 0.128 & $9.29 \times 10^{-3}$ & -422 & 0.001 & $7.93 \times 10^{-1}$ & -415 \\
\hline$t-1$ & 0.151 & $4.37 \times 10^{-3}$ & -423 & 0.063 & $7.31 \times 10^{-2}$ & -418 & 0.181 & $1.67 \times 10^{-3}$ & -425 \\
\hline$t-2$ & 0.090 & $3.07 \times 10^{-2}$ & -420 & 0.006 & $5.95 \times 10^{-1}$ & -415 & 0.008 & $5.22 \times 10^{-1}$ & -415 \\
\hline$t-3$ & 0.008 & $5.07 \times 10^{-1}$ & -415 & 0.043 & $1.41 \times 10^{-1}$ & -417 & 0.050 & $1.12 \times 10^{-1}$ & -417 \\
\hline$t-4$ & 0.042 & $1.43 \times 10^{-1}$ & -417 & 0.173 & $2.16 \times 10^{-3}$ & -424 & 0.004 & $6.73 \times 10^{-1}$ & -415 \\
\hline$t-5$ & 0.091 & $2.94 \times 10^{-2}$ & -420 & 0.083 & $3.82 \times 10^{-2}$ & -419 & 0.047 & $1.25 \times 10^{-1}$ & -417 \\
\hline$t-6$ & 0.009 & $4.93 \times 10^{-1}$ & -415 & 0.035 & $1.86 \times 10^{-1}$ & -416 & 0.027 & $2.47 \times 10^{-1}$ & -416 \\
\hline$t-7$ & 0.002 & $7.57 \times 10^{-1}$ & -415 & 0.138 & $6.77 \times 10^{-3}$ & -422 & 0.047 & $1.26 \times 10^{-1}$ & -408 \\
\hline$t-8$ & 0.176 & $1.98 \times 10^{-3}$ & -425 & 0.119 & $1.21 \times 10^{-2}$ & -421 & 0.023 & $2.90 \times 10^{-1}$ & -399 \\
\hline \multicolumn{10}{|c|}{ Zone 2} \\
\hline & \multicolumn{3}{|c|}{$Y_{z 2}, L$} & \multicolumn{3}{|c|}{$Y_{z 2}, P_{n}$} & \multicolumn{3}{|c|}{$Y_{z 2}, I_{j}$} \\
\hline$t$ & 0.182 & $1.62 \times 10^{-3}$ & -310 & 0.181 & $1.69 \times 10^{-3}$ & -310 & 0.001 & $8.13 \times 10^{-1}$ & -300 \\
\hline$t-1$ & 0.223 & $4.03 \times 10^{-4}$ & -313 & 0.259 & $1.19 \times 10^{-4}$ & -315 & 0.006 & $5.87 \times 10^{-1}$ & -300 \\
\hline$t-2$ & 0.192 & $1.15 \times 10^{-3}$ & -311 & 0.297 & $2.95 \times 10^{-5}$ & -318 & 0.020 & $3.14 \times 10^{-1}$ & -301 \\
\hline$t-3$ & 0.228 & $3.41 \times 10^{-4}$ & -313 & 0.313 & $1.60 \times 10^{-5}$ & -319 & 0.008 & $5.22 \times 10^{-1}$ & -300 \\
\hline$t-4$ & 0.326 & $9.91 \times 10^{-6}$ & -320 & 0.403 & $4.39 \times 10^{-7}$ & -327 & 0.109 & $1.66 \times 10^{-2}$ & -306 \\
\hline$t-5$ & 0.295 & $3.22 \times 10^{-5}$ & -318 & 0.398 & $5.45 \times 10^{-7}$ & -326 & 0.082 & $3.93 \times 10^{-2}$ & -304 \\
\hline$t-6$ & 0.257 & $1.27 \times 10^{-4}$ & -315 & 0.289 & $3.91 \times 10^{-5}$ & -318 & 0.003 & $2.87 \times 10^{-1}$ & -301 \\
\hline$t-7$ & 0.290 & $3.83 \times 10^{-5}$ & -318 & 0.287 & $4.26 \times 10^{-5}$ & -317 & 0.034 & $1.94 \times 10^{-1}$ & -295 \\
\hline$t-8$ & 0.337 & $6.43 \times 10^{-6}$ & -321 & 0.296 & $3.01 \times 10^{-5}$ & -318 & 0.047 & $2.68 \times 10^{-2}$ & -289 \\
\hline \multicolumn{10}{|c|}{ Zone 3} \\
\hline & \multicolumn{3}{|c|}{$Y_{z 3}, L$} & \multicolumn{3}{|c|}{$Y_{z 3}, P_{n}$} & \multicolumn{3}{|c|}{$Y_{z 3}, I_{g}$} \\
\hline$t$ & 0.301 & $2.58 \times 10^{-5}$ & -271 & 0.361 & $2.48 \times 10^{-6}$ & -275 & 0.040 & $1.55 \times 10^{-1}$ & -254 \\
\hline$t-1$ & 0.371 & $1.64 \times 10^{-6}$ & -276 & 0.382 & $1.04 \times 10^{-6}$ & -277 & 0.001 & $8.87 \times 10^{-1}$ & -252 \\
\hline$t-2$ & 0.355 & $3.13 \times 10^{-6}$ & -275 & 0.467 & $2.39 \times 10^{-8}$ & -285 & 0.115 & $1.39 \times 10^{-2}$ & -258 \\
\hline$t-3$ & 0.419 & $2.18 \times 10^{-7}$ & -280 & 0.516 & $2.09 \times 10^{-9}$ & -290 & 0.031 & $2.11 \times 10^{-1}$ & -254 \\
\hline$t-4$ & 0.425 & $1.65 \times 10^{-7}$ & -281 & 0.532 & $8.62 \times 10^{-10}$ & -291 & 0.046 & $1.26 \times 10^{-1}$ & -254 \\
\hline$t-5$ & 0.353 & $3.45 \times 10^{-6}$ & -275 & 0.438 & $9.10 \times 10^{-8}$ & -282 & 0.034 & $1.90 \times 10^{-1}$ & -254 \\
\hline$t-6$ & 0.391 & $7.08 \times 10^{-7}$ & -278 & 0.389 & $7.88 \times 10^{-7}$ & -278 & 0.030 & $2.19 \times 10^{-1}$ & -254 \\
\hline$t-7$ & 0.390 & $7.41 \times 10^{-7}$ & -278 & 0.309 & $1.91 \times 10^{-5}$ & -271 & 0.005 & $6.19 \times 10^{-1}$ & -252 \\
\hline$t-8$ & 0.465 & $2.56 \times 10^{-8}$ & -284 & 0.392 & $6.93 \times 10^{-7}$ & -278 & 0.024 & $2.82 \times 10^{-1}$ & -253 \\
\hline
\end{tabular}


lowest AIC values at $p<0.05$. The dependent variables $Y_{z 1}, Y_{z 2}$ and $Y_{z 3}$ had significantly high correlations with the independent variables of LOTI for the latitude band $0^{\circ} \mathrm{N}$ to $24^{\circ} \mathrm{S}(L)$, PWI for the month of September $\left(P_{s}\right)$ and November $\left(P_{n}\right)$ and SOI for the month of April $\left(I_{a}\right)$, July $\left(I_{j}\right)$ and August $\left(I_{g}\right)$. LOTI had highest correlation at year $t-8$ for all three zones while PWI had strongest correlation at year $t-4$ in all three cases with $P_{s}$ for $Y_{z 1}$ and $P_{n}$ for $Y_{z 2}$ and $Y_{z 3}$. SOI showed most significant correlation for $I_{a}$ at year $t-1$ with $Y_{z 1}, I_{j}$ at year $t-4$ for $Y_{z 2}$ and $I_{g}$ at year $t-2$ for $Y_{z 3}$. These independent variables were also accepted on the basis that these are climatic conditions fall within or in close proximation the data coverage zone for the CPUE of the yellowfin tuna in Zone 1, Zone 2 and Zone 3.

When regression analysis is used sometimes spurious correlations may arise. To detect this we performed unit root tests which are statistical methods to identify cases of unauthentic correlations [19]-[21] for all the time series data used in this study. Results of MacKinnon's test (M-test) and Augmented Dickey-Fuller test (ADF-test) having t-test value (t-value) of $<0$ and significance level of $p<0.05$ were positive for having stationary process (Table 2). The outcome of the unit root tests showed that all the time series variables from Table 1 showed stationarity and did not have a unit root processes and the relationships shown in Table 1 are authentic.

\subsection{Stock Reproduction Model}

The results for stock reproduction models for the CPUE of the yellowfin tuna in the South Pacific Zone 1, Zone 2 and Zone 3 using the independent variables from Table 1 are shown in Table 3. We have only shown three models for each area which had the highest $R^{2}$ and lowest AIC values with $p<0.05$. For the yellowfin tuna in Zone 1 model (i) has the highest $R^{2}$ and lowest AIC value and it incorporates the independent variables $L_{t-8}$, $P_{s, t-4}$ and $I_{a, t-1}$. For Zone 2 model (iv) is most significant with respect to $R^{2}$, AIC and $p$-value and incorporates $L_{t-8}, P_{n, t-4}$ and $I_{j, t-4}$. The most suitable model for the yellowfin tuna in Zone 3 is model (vii) which incorporates $L_{t-8}, P_{n, t-4}$ and $I_{g, t-2}$ as the independent variables (Table 3 ).

Collinearity tests did not show any significantly high correlations between any of the independent variables incorporated into the final models in Table 3. Homogeneity tests showed that all model residuals shown in Table 3 have a variance of $<0.1$ which fulfills the requirements of homogeneity where variance needs to be $<4.00$ for the least square estimators to be reliable [26] (Figure 6).

Figure 7 shows the plot of CPUE of the yellowfin tuna (T. albacares) in Zone 1 and the CPUE trajectory from model (i) (Table 3). The CPUE predicted seems to fit quite well with the CPUE referred. In Figure 8 and Figure 9 the referred CPUE trajectory of yellowfin tuna in in Zone 2 and Zone 3 are shown with the CPUE trajectory resulting from model (iv) and (vii) (Table 3). The fitness of the predicted CPUE with the referred CPUE is highest for Zone 3 followed by Zone 2 and Zone 1. The linear correlations of the models shown in Table 3 are shown in Figure 10. The determination coefficients for the yellowfin tuna CPUE referred for Zone 1, Zone 2 and Zone 3 against the CPUE predicted from models (i), (iv) and (vii) (Table 3, Figure 10) are 0.602, 0.698 and

Table 2. Results of unit root tests for variables used in regression analysis from Table 1.

\begin{tabular}{ccccc}
\hline \multicolumn{2}{c}{ Series } & M-test & \multicolumn{2}{c}{ ADF-test } \\
\cline { 2 - 4 } & t-value & $p$-value & t-value & $p$-value \\
\hline$Y_{z 1} 1957-2008$ & -7.749 & $5.28 \times 10^{-10}$ & -7.749 & $<1.00 \times 10^{-2}$ \\
$Y_{z 2} 1957-2008$ & -7.851 & $3.70 \times 10^{-10}$ & -7.851 & $<1.00 \times 10^{-2}$ \\
$Y_{z 3} 1957-2008$ & -11.390 & $3.02 \times 10^{-15}$ & -11.390 & $<1.00 \times 10^{-2}$ \\
$L_{1} 1949-2008$ & -8.656 & $6.51 \times 10^{-12}$ & -8.656 & $<1.00 \times 10^{-2}$ \\
$P_{s} 1949-2008$ & -13.370 & $<2.20 \times 10^{-16}$ & -13.369 & $<1.00 \times 10^{-2}$ \\
$P_{n} 1949-2008$ & -10.750 & $3.12 \times 10^{-15}$ & -10.750 & $<1.00 \times 10^{-2}$ \\
$I_{a} 1951-2008$ & -9.221 & $1.11 \times 10^{-12}$ & -9.221 & $<1.00 \times 10^{-2}$ \\
$I_{j} 1951-2008$ & -11.546 & $3.31 \times 10^{-16}$ & -11.546 & $<1.00 \times 10^{-2}$ \\
$I_{g} 1951-2008$ & -13.230 & $<2.20 \times 10^{-16}$ & -13.230 & \\
\hline
\end{tabular}




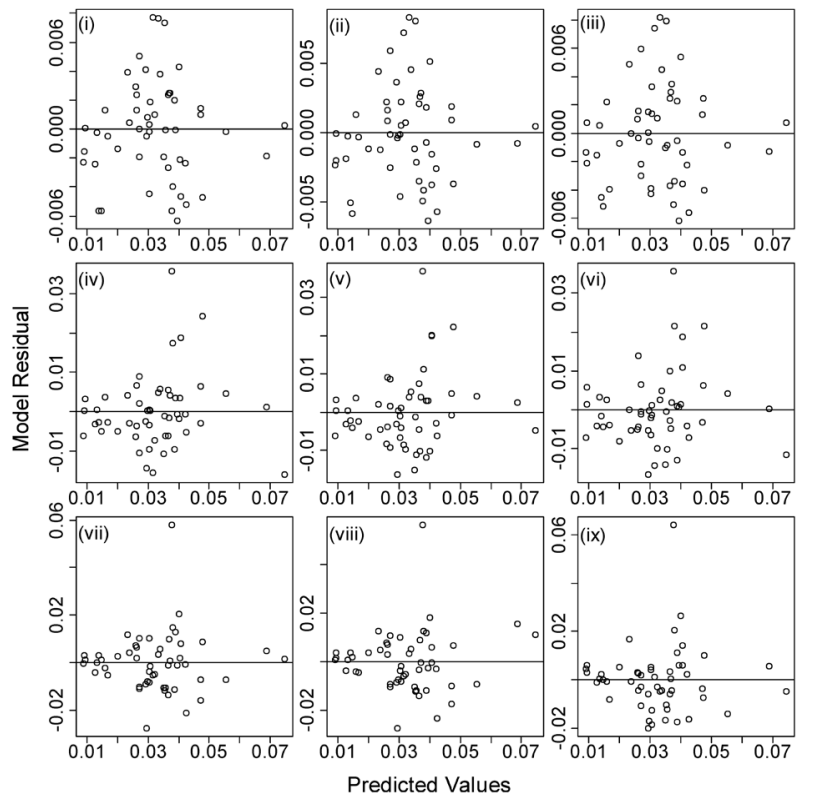

Figure 6. The residuals of models from Table 3 against the predicted values. Top panel are for Zone 1 , middle panel for Zone 2 and bottom panel for Zone 3 . The residual variance in all cases is $<0.08$.

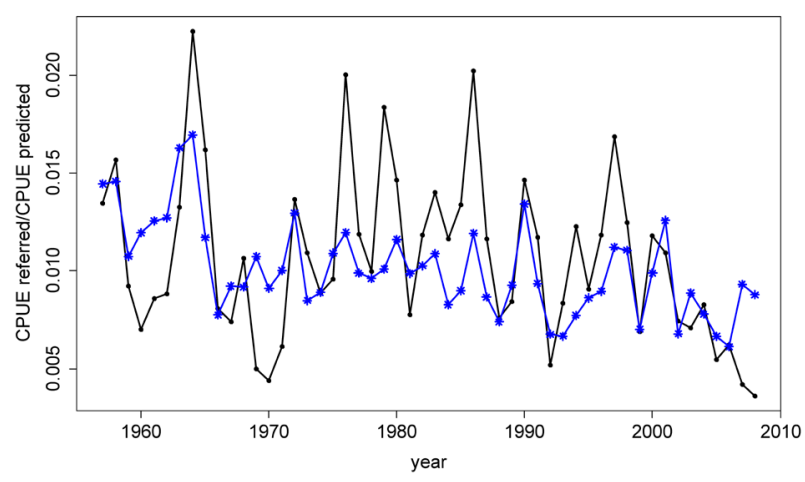

Figure 7. Graph showing the CPUE time series trajectory of the yellowfin tuna (T. albacares) stock in Zone 1 for the years 1957-2008. The referred CPUE is shown in black and the trajectory which resulted from model i (Table 3) is shown in blue.

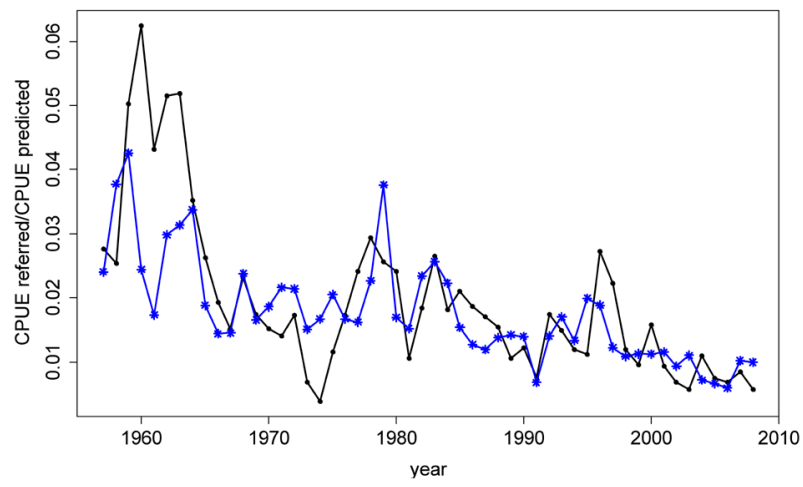

Figure 8. Graph showing the CPUE time series trajectory of the yellowfin tuna (T. albacares) stock in Zone 2 for the years 1957-2008. The referred CPUE is shown in black and the trajectory which resulted from model iv (Table 3 ) is shown in blue. 


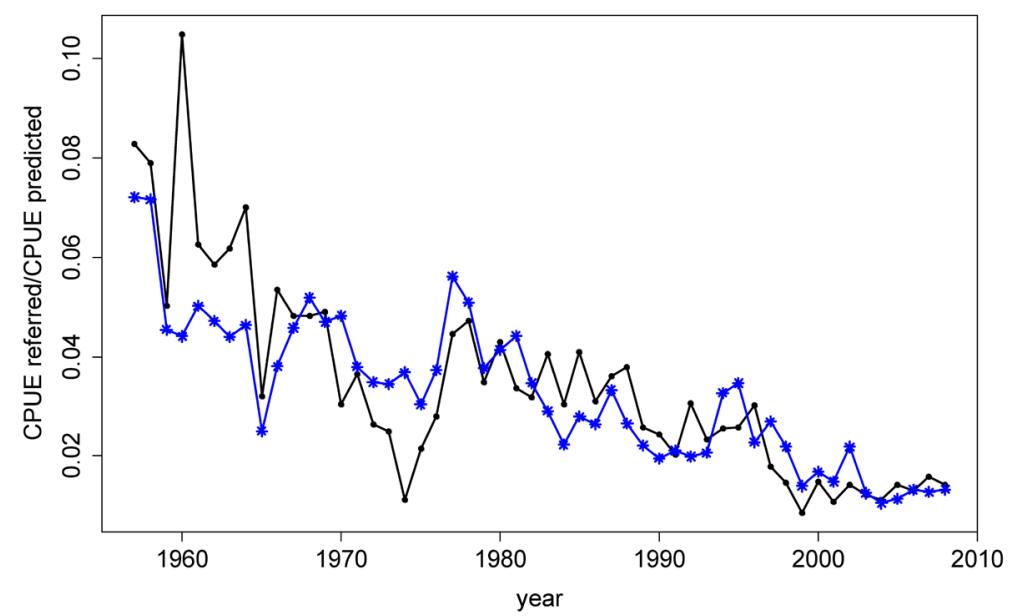

Figure 9. Graph showing the CPUE time series trajectory of the yellowfin tuna (T. albacares) stock in Zone 3 for the years 1957-2008. The referred CPUE is shown in black and the trajectory which resulted from model vii (Table 3) is shown in blue.

Table 3. Stock reproduction models and some parameters using the independent variables $L, P$ and $I$ from Table 1 for the yellowfin tuna (T. albacares) stock in Zone 1, Zone 2 and Zone 3 of the South Pacific Ocean. Values are only shown for statistically most significant model at $p<0.05$.

\begin{tabular}{|c|c|c|c|c|c|}
\hline \multicolumn{6}{|c|}{ Zone 1} \\
\hline & Model & $R^{2}$ & $\mathrm{t}$-value & $p$-value & AIC \\
\hline 1) & $\begin{aligned} \ln \left(Y_{21, t}\right)=- & 4.69+2.38 \times 10^{-4} \times L_{t-8}^{2}-3.43 \times 10^{-6} \times L_{t-8}^{3} \\
& -0.63 \times P_{s, t-4}+9.31 \times 10^{-2} \times I_{a, t-1}\end{aligned}$ & 0.362 & 5.326 & $2.39 \times 10^{-6}$ & -438 \\
\hline 2) & $\begin{aligned} \ln \left(Y_{z 1, t}\right)= & -4.70+2.60 \times 10^{-4} \times L_{t-8}^{2}-3.89 \times 10^{-6} \times L_{t-8}^{3} \\
& -0.66 \times P_{s, t-4}+1.86 \times 10^{-2} \times I_{a, t-1}^{3}\end{aligned}$ & 0.341 & 5.090 & $5.45 \times 10^{-6}$ & -436 \\
\hline 3) & $\begin{aligned} \ln \left(Y_{z 1, t}\right)=- & 4.74+2.34 \times 10^{-4} \times L_{t-8}^{2}-3.78 \times 10^{-6} \times L_{t-8}^{3} \\
& -0.73 \times P_{s, t-4}+4.40 \times 10^{-2} \times I_{a, t-1}^{2}\end{aligned}$ & 0.320 & 4.845 & $1.27 \times 10^{-5}$ & -435 \\
\hline \multicolumn{6}{|c|}{ Zone 2} \\
\hline 4) & $\begin{aligned} \ln \left(Y_{z 2, t}\right)=- & 4.11-1.25 \times 10^{-2} \times L_{t-8}+3.25 \times 10^{-4} \times L_{t-8}^{2}+4.06 \times P_{n, t-4}^{2} \\
& -5.68 \times P_{n, t-4}^{3}-5.51 \times 10^{-2} \times\left(L_{t-8} \times P_{n, t-4}\right)+8.48 \times 10^{-2} \times I_{j, t-4}\end{aligned}$ & 0.487 & 6.893 & $8.83 \times 10^{-9}$ & -334 \\
\hline 5) & $\begin{aligned} \ln \left(Y_{z 2, t}\right)= & -3.97-1.48 \times 10^{-2} \times L_{t-8}+2.85 \times 10^{-4} \times L_{t-8}^{2} \\
& -3.87 \times 10^{-2} \times\left(L_{t-8} \times P_{n, t-4}\right)+0.115 \times I_{j, t-4}\end{aligned}$ & 0.443 & 6.299 & $7.49 \times 10^{-8}$ & -330 \\
\hline 6) & $\ln \left(Y_{z 2, t}\right)=-3.95-8.98 \times 10^{-3} \times L_{t-8}-4.35 \times P_{n, t-4}^{3}+9.20 \times 10^{-2} \times I_{j, t-4}$ & 0.438 & 6.238 & $9.32 \times 10^{-8}$ & -330 \\
\hline \multicolumn{6}{|c|}{ Zone 3} \\
\hline & $\ln \left(Y_{z 3, t}\right)=-3.38-1.42 \times 10^{-6} \times L_{t-8}^{3}-1.54 \times P_{n, t-4}+6.37 \times 10^{-2} \times I_{g, t-2}$ & 0.635 & 9.323 & $1.61 \times 10^{-12}$ & -304 \\
\hline & $\ln \left(Y_{z 3, t}\right)=-3.34-9.65 \times 10^{-5} \times L_{t-8}^{2}-1.53 \times P_{n, t-4}+6.44 \times 10^{-2} \times I_{g, t-2}$ & 0.624 & 9.115 & $3.30 \times 10^{-12}$ & -303 \\
\hline 9) & $\begin{aligned} \ln \left(Y_{z 3, t}\right)=- & 3.39-1.55 \times 10^{-4} \times L_{t-8}^{2}+2.87 \times P_{n, t-4}^{2} \\
& -10.72 \times P_{n, t-4}^{3}+6.48 \times 10^{-2} \times I_{g, t-2}\end{aligned}$ & 0.573 & 8.186 & $8.58 \times 10^{-11}$ & -296 \\
\hline
\end{tabular}




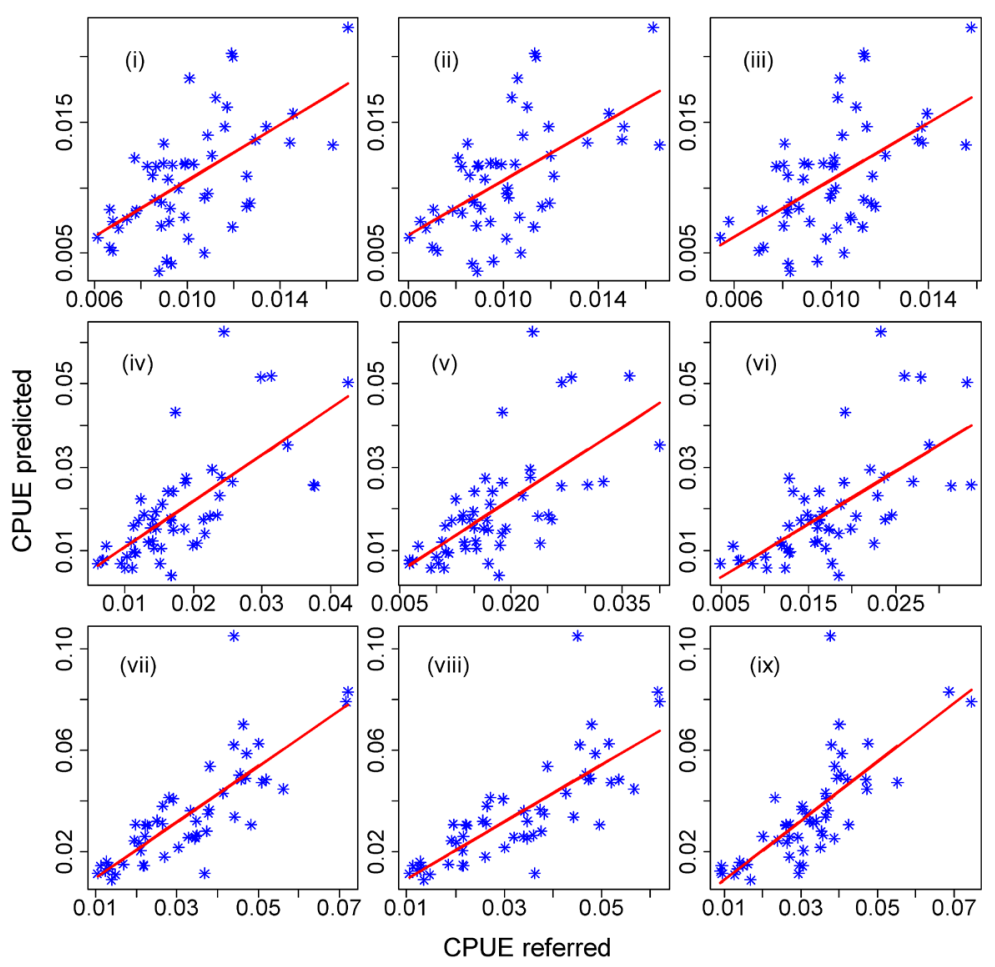

Figure 10. The linear relationship between the CPUE predicted and CPUE referred for the yellowfin tuna (T. albacares) stock in the South Pacific Ocean Zone 1 (top panel), Zone 2 (middle panel) and Zone 3 (bottom panel). The numbers refer to the models presented in Table 3.

0.797 respectively. The slope for (Figure 10(i)) is 1.064 with $95 \%$ confidence interval of $(0.663,1.465)$, for (Figure 10(iv)) the slope is 1.104 with 95\% confidence interval of $(0.782,1.425)$ and for (Figure 10(vii)) the slope is 1.098 with $95 \%$ confidence interval of $(0.862,1.335)$. In all three cases the slopes are not significantly different from unity.

Figure 11 shows the time series fluctuation patterns for the independent variables $L, P$ and $I$ which resulted in the most statistically significant models for the CPUE trajectory of the yellowfin tuna in the South Pacific Zone 1, Zone 2 and Zone 3 from models (i), (iv) and (vii) (Table 3). Both LOTI and PWI seem to have a gradually increasing pattern from 1949 to 2008 while SOI seems to fluctuate between highs and lows while running approximately parallel to the x-axis from 1951 to 2008. Exploratory analysis showed the presence of relationship of the SOI incorporated into the models for Zone $1\left(I_{a}\right)$, Zone $2\left(I_{j}\right)$ and Zone $3\left(I_{g}\right)$ with the climatic conditions of the Pacific Decadal Oscillation (PDO) for the month of September and Niña 3 which is the Eastern Tropical Pacific sea surface temperature $\left(5^{\circ} \mathrm{N}-5^{\circ} \mathrm{S}, 150^{\circ} \mathrm{W}-90^{\circ} \mathrm{W}\right)$ (Figure 12). Due to their interrelation and high collinearity only SOI was selected for modeling as it was most significant among these variables.

\section{Discussion}

Before making management plans and mitigation procedures for the conservation and sustainability of any fishery stock it is imperative to first understand the underlying factors behind its time series fluctuation pattern. This study was carried out in order to better understand the stock dynamics of the yellowfin tuna in the Eastern and Western South Pacific Ocean Zone 1, Zone 2 and Zone 3 (Figure 1) from 1957 to 2008. From Figure 5 the differences in stock dynamics in the three zones are evident. The catch levels are significantly higher in Zone 3 compared with Zone 1 and Zone 2 where the catch levels differed to a lesser magnitude with catch levels in Zone 1 being the lowest. Similar pattern can be observed for CPUE trajectory where the CPUE in Zone 3 is significantly higher than Zone 2 and Zone 1 which had smaller differences with Zone 1 having the lowest CPUE. From this it can be inferred that historically stock levels have been considerably higher in Zone 3 compared with Zone 2 and Zone 1. In the mid-1990s the CPUE in Zone 3 reached lower levels and became analogous with Zone 2 and Zone 1 up to 2008. Conversely the catch levels in Zone 3 have been retained high during this period 

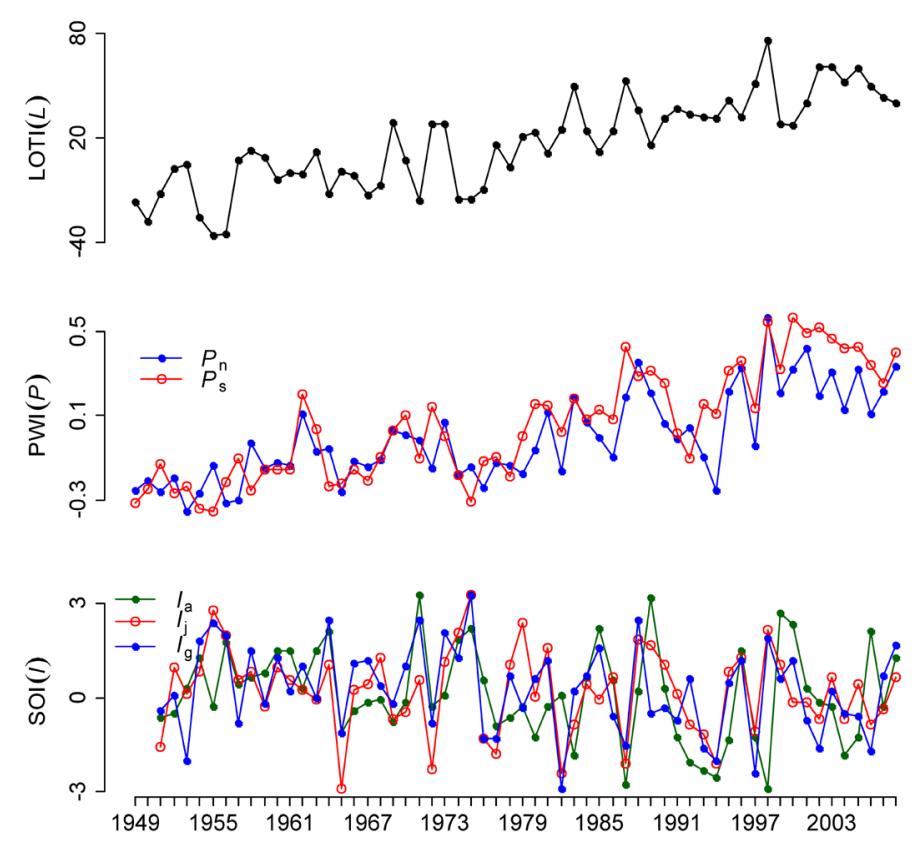

Figure 11. Time series pattern of the climatic conditions. Graphs from top; the global mean land and ocean temperature index LOTI for the latitude band $0^{\circ} \mathrm{N}$ to $24^{\circ} \mathrm{S}(L)$, Pacific warm pool index (PWI) for the month of September $\left(P_{s}\right)$ and November $\left(P_{n}\right)$ and Southern Oscillation Index (SOI) for the month of April $\left(I_{a}\right)$, July $\left(I_{j}\right)$ and August $\left(I_{g}\right)$.
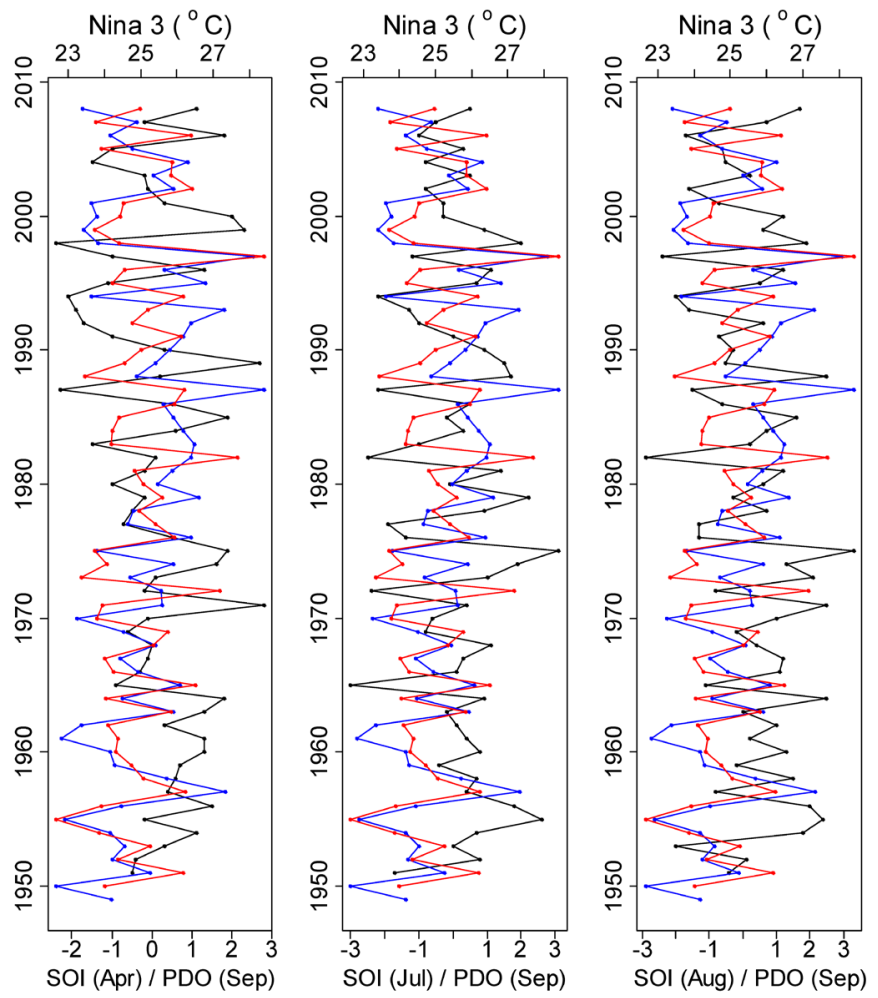

Figure 12. Relationship of the SOI incorporated into the models for Zone $1\left(I_{a}\right)$, Zone $2\left(I_{i}\right)$ and Zone 3 $\left(I_{q}\right)$ (black line) with the climatic conditions of the Pacific Decadal Oscillation (PDO) for the month of September (blue line) and Niña 3 (red line) which is the Eastern Tropical Pacific sea surface temperature $\left(5^{\circ} \mathrm{N}-5^{\circ} \mathrm{S} 150^{\circ} \mathrm{W}-90^{\circ} \mathrm{W}\right)$. SOI exhibits negative relationship with both PDO and Niña 3. La Niña episodes occur during positive SOI while El Niño events happen during negative SOI. 
through significant increase in exploitation efforts (Figure 3 and Figure 5) which could lead to the overexploitation of the yellowfin tuna stock in Zone 3 if they are left unchecked. Such assumptions for tuna stocks based on fishing effort alone may be true to some extent but it is not precise as the effect of climatic conditions in altering tuna stock dynamics has been documented, which needs to be further studied and taken into account [8] [9] [12]-[14].

For this study we decided to use the CPUE data over the catch data for regression analysis and developing the stock reproduction model. From Figure 3 it can be seen that the effort does not remain constant over time and follows a similar pattern to the catch trajectory with different degrees of similarities for each zone (Figure 4) whereas the CPUE is the catch calculated for each unit of effort. The CPUE is therefore a better representative of the stock dynamics of the yellowfin tuna compared with catch. When using CPUE to represent stock status of a fishery it is assumed that the strength of a unit of effort used to exploit the fishery remains constant over time. Hampton and Fournier [17] have shown that the longline catchability of yellowfin tuna in the Western and Central Pacific Ocean (WCPO) area has remained relatively constant over time and that CPUE is a suitable representative of the stock abundance of the exploitable biomass.

From regression analysis, the climatic condition variables, PWI, LOTI and SOI have significantly high correlation with the yellowfin tuna CPUE in Zone 1, Zone 2 and Zone 3 (Table 1). The PWI is the sea surface temperature index of a specific and substantial area in the WCPCA where the temperature is higher than average. The LOTI is an index of the sea and land surface air temperature of the latitude band $0^{\circ} \mathrm{N}$ to $24^{\circ} \mathrm{S}$ which cuts across the South Pacific and falls within the data coverage area. SOI comprises of large scale alterations in atmospheric mass or air pressure anomalies between the Western and Eastern tropical and sub-topical Southern Pacific. It is calculated based on the sea level pressure anomalies differences at Darwin $\left(12^{\circ} \mathrm{S}\right.$ to $\left.130^{\circ} \mathrm{E}\right)$ and $\mathrm{Ta}-$ hiti $\left(17^{\circ} \mathrm{S}\right.$ to $\left.149^{\circ} \mathrm{W}\right)$ [29]. La Niña episodes occur during positive SOI while El Niño events happen during negative SOI (Figure 12). The relationship of PWI, LOTI and SOI to yellowfin tuna makes ecological sense as all three of these climatic conditions are located within Zone 1, Zone 2 and Zone 3 data coverage area.

For all three zones the final models incorporate $L, P$ and $I$ as the independent climatic variables (Table 3) with different months and lag periods. LOTI results in most significant models with lag period of $t-8\left(L_{t-8}\right)$ for Zone 1, Zone 2 and Zone 3. This falls within the lifespan of yellowfin tuna which is around 5 to 8 years [16] [17]. It can be inferred that LOTI influences the spawning and early life stages of the yellowfin tuna in all three zones of the South Pacific Ocean. PWI fits to the most significant models for Zone 1 in the month of September $\left(P_{s}\right)$ and for Zone 2 and Zone 3 in the month of November $\left(P_{n}\right)$ with lag of $t-4$ for all three zones. Lehodey [12] has shown that the yellowfin tuna population is linked to the Pacific warm pool. Graham [30] and Maldenya [31] investigated the stomach contents of yellowfin tuna and found that their diet changed significantly between $45 \mathrm{~cm}$ and $50 \mathrm{~cm}$ fork length. Kuhnert [32] showed that the dietary preferences of yellowfin tuna differed in relation to their size, sea surface temperature and latitude. It is possible that the alteration in PWI influences the prey distribution and availability for the yellowfin tuna when they make transformations in their diet. The SOI incorporated into the most suitable models (Table 3 ) differed by month and lag periods for Zone 1 ( $\left.I_{a, t-1}\right)$, Zone $2\left(I_{j, t-4}\right)$ and Zone $3\left(I_{g, t-2}\right)$. Lehodey [12] showed that primary production and prey distribution for tuna is influenced by changes in SOI. The difference in the lag periods for the SOI might be attributed to its influence on the spatial distribution of various prey in relation to the different dietary preferences and life stages of the yellowfin tuna in Zone 1, Zone 2 and Zone 3 [30]-[32]. The effect of SOI on small fish species has been previously reported [33] [34]. Lehodey [12] showed that the recruitment of yellowfin tuna was favorable during positive Pacific Decadal Oscillation (PDO) and El Niño events and unfavorable during negative PDO and La Niña events. El Niño and La Niña events result in the easterly and westerly migrations of the Pacific warm pool and causing changes in the temperature and salinity of the water in the area [35]-[37]. Indeed, exploratory analysis shows strong link between yellowfin tuna in Zone 1, Zone 2 and Zone 3 and the climatic condition of SOI, El Niño, La Niña and PDO as they are interrelated climatic conditions (Figure 12).

The time series trajectory of yellowfin tuna in Zone 1, Zone 2 and Zone 3 can be written in relation to the climatic conditions as

$$
Y_{r, t}=a \cdot f\left(v_{1, t-n}, v_{2, t-n}, \cdots, v_{k, t-n}\right)
$$

where $Y_{r, t}$ is the CPUE in the coverage zone $r$, year $t$ and $f()$ is the function determined by the climatic factors $v_{i}$ $(i=1,2, \cdots, k)$ with $n=(0,1, \cdots, 8)$. Equation (3) shows the mechanism which is followed by the yellowfin tuna in all three zones of the Eastern and Western South Pacific. The models for all three zones fit quite well to the 
referred CPUE from Figures 7-9.

From Table 3 and Figure 10 it can be seen that the fitted models for yellowfin tuna get more significant from Zone 1 to Zone 2 and Zone 3 being the most significant. From Figure 3 and Figure 4 the relationship of between catch and effort is highest for Zone 1 followed by Zone 2 and the lowest for Zone 3 . This phenomenon can be observed in Figure 4 and Figure 10 where the closer (further) the points scatter from the slope line the lower (higher) the bias between the relationship of the catch and effort and the predicted and referred CPUE. Based on this we can state that the larger proportion of the stock time series pattern for yellowfin tuna in Zone 3 is due to the alterations in the climatic conditions of LOTI, PWI and SOI with the trajectory for Zone 2 being affected less than Zone 3 and Zone 1 although significant, being the least affected by the three climatic conditions. This coincides with the catch and effort relationship where the catch trajectory in Zone 1 is mostly determined by the effort level followed by Zone 2 with the lowest being Zone 3. The effect of the climatic conditions of LOTI, PWI and SOI on yellowfin tuna stock gets more pronounced as we move from the Western to the Eastern South Pacific Ocean.

It might be possible that the Island nations and territories which fall within the WCPCA might not be taking the declining stock status of the yellowfin tuna with reference to the CPUE (Figure 5) more seriously and making significant conservation efforts as it can be seen from Figure 5 that even until recently catch levels can still be maintained high. The increase in catch is significantly determined by the increase in effort (Figure 3 and Figure 4) especially for Zone 1. Miyake [38] outlines the rapid development of yellowfin tuna commercial fisheries in the WCPO from the mid-1980s. As shown in [17] yield analysis of yellowfin tuna data for the WCPO area show that catches have been quite high and may have even exceeded the maximum sustainable yield (MSY) over the three decades from the 1970s to 1990s.

From the stock reproduction models for the yellowfin tuna in Zone 1, Zone 2 and Zone 3 it is evident that a significantly high proportion of the CPUE time series fluctuation patterns are due to changes in the LOTI, PWI and SOI. The slopes in Figure 10 are not significantly different from unity and this is further evidence that these climatic conditions have a strong influence on the stock trajectory of yellowfin tuna in all three areas. As the trajectory for yellowfin tuna has historically been affected by LOTI, PWI and SOI (Figures 7-9), if the climatic pattern continues, it can be expected that the future CPUE especially for Zone 2 and Zone 3 might continue to decrease in the future. Since it is highly improbable to control the trajectories of climatic conditions and even less without international cooperation, conservation efforts should be directed at factors that can be controlled more practically by human intervention such as the fishing effort. Sustainability efforts for future yellowfin tuna stock should be done by reducing the effort levels to increase the CPUE rather than increasing effort levels to increase catch. While adherence to such recommendation can lead to the biological sustainability of the yellowfin tuna stock, it will probably have negative impact on the economic gains from yellowfin tuna harvest for countries within the Eastern and Western South Pacific. It is necessary to develop suitable plans to control the effort level such as to ensure both the biological and economical sustainability of the yellowfin tuna stock.

Miller [39] has outlined the effects of various climatic conditions on the abundance and distribution of various pelagic fish stocks. It was also noted that tuna species including yellowfin tuna abundance and spatial distribution are quite sensitive to changes in climatic condition. Tropical tuna including yellowfin need continuous access to rich food sources because of their high metabolic rate, production and short life spans. They are constantly swimming in search of food and their distribution is highly dependent on aquatic processes which result in high concentration of food resources. These processes are a result of short term and long term variability in climatic conditions [12] [40] [41].

The resulting dynamic behaviors of biological populations in aquatic ecosystems are complex and are affected by the interaction of numerous intrinsic and extrinsic factors [42]. Further work needs to be done in order to establish how the climate variables interrelate to affect yellowfin tuna fishery in the South Pacific Ocean. The understanding of the effects of these processes on the trajectory and distribution pattern of the yellowfin tuna will help to make more informed decisions regarding the yellowfin tuna fisheries in the Eastern and Western South Pacific. With the models developed in this study, the climatic condition of LOTI, PWI and SOI combined with the effects of fishing pressure (effort) accounts for a major proportion of the abundance of exploitable yellowfin tuna stock in the Eastern and Western South Pacific. When management decisions are made regarding the fisheries of yellowfin tuna including fishing quotas in these areas it is imperative to also take the effect of climatic conditions into account. From the resulting stock dynamics in this study and due to the substantial residency and production of yellowfin tuna within each EEZ in the WCPO according to Silbert [2], it can be said that while 
international managements arrangements are necessary for the sustainability of yellowfin tuna stocks in the South Pacific, domestic conservation policies are imperative for management of yellowfin tuna stocks within the EEZs of South Pacific Island nations and territories.

\section{Acknowledgements}

We wish to extend our gratitude to many fishers, research scientists and individuals who aided in the gathering of data on the climatic conditions and yellowfin tuna stock over the years.

\section{References}

[1] Hampton, J. (2010) Tuna Fisheries Status and Management in the Western and Central Pacific Ocean. Background Paper, Oceanic Fisheries Programme, Secretariat of the Pacific Community, Noumea.

[2] Silbert, J. and Hampton, J. (2003) Mobility of Tropical Tunas and the Implications for Fisheries Management. Marine Policy, 27, 87-95. http://dx.doi.org/10.1016/S0308-597X(02)00057-X

[3] Aaheim, A. and Signa, L. (2000) Economic Impacts of Climate Change on Tuna Fisheries in Fiji Islands and Kiribati. CICERO Report, No. 4, Center for International Climate and Environmental Research, Blindern. http://hdl.handle.net/11250/191936

[4] Lawson, T.A. (2000) Secretariat of the Pacific Community Tuna Fishery Yearbook 1999. Secretariat of the Pacific Community, Noumea.

[5] Gillett, R., McCoy, M., Rodwell, R. and Tamate, J. (2001) Fisheries in the Economies of Pacific Island Countries and Territories. Pacific Studies Series, Asian Development Bank, Manila.

[6] Bell, J.D., Reid, C., Batty, M.J., Lehodey, P., Rodwell, L., Hobday, A.J., Johnson, J.E. and Demmke, A. (2013) Effects of Climate Change on Oceanic Fisheries in the Tropical Pacific: Implications for Economic Development and Food Security. Climate Change, 119, 199-212. http://dx.doi.org/10.1007/s10584-012-0606-2

[7] Schaefer, K.M., Fuller, D.W. and Block, B.A. (2007) Movements, Behaviour, and Habitat Utilization of Yellowfin tuna (Thunnus albacares) in the Northeastern Pacific Ocean, Ascertained through Archival Tag data. Marine Biology, 152, 503-525. http://dx.doi.org/10.1007/s00227-007-0689-X

[8] Lehodey, P., Hampton, J., Brill, R.W., Nicol, S., Senina, I., Calmettes, B., Portner, H.O., Bopp, L., Ilyina, T., Bell, J.D. and Sibert, J. (2011) Vulnerability of Oceanic Fisheries in the Tropical Pacific to Climate Change. In: Bell, J.D., Jhonson, J.E. and Hobday, A.J., Eds., Vulnerability of Tropical Pacific Fisheries and Aquaculture to Climate Change, Secretariat of the Pacific Community, Noumea, 435-484.

[9] Lehodey, P., Bertignac, M., Hampton, J., Lewis, T. and Picaut, J. (1997) El Niño-Southern Oscillation and Tuna in the Western Pacific. Nature, 389, 715-718. http://dx.doi.org/10.1038/39575

[10] Lehodey, P. (2001) The Pelagic Ecosystem of the Tropical Pacific Ocean: Dynamic Spatial Modeling and Biological Consequences of ENSO. Progress in Oceanography, 49, 439-468. http://dx.doi.org/10.1016/S0079-6611(01)00035-0

[11] Dufour, F., Arrizabalaga, H., Irigoien, X. and Santiago, J. (2010) Climate Impacts on Albacore and Bluefin Tunas Migrations Phenology and Spatial Distribution. Progress in Oceanography, 86, 283-290. http://dx.doi.org/10.1016/j.pocean.2010.04.007

[12] Lehodey, P., Chai, F. and Hampton, J. (2003) Modelling Climate-Related Variability of Tuna Populations from a Coupled Ocean-Biogeochemical-Populations Dynamics Model. Fisheries Oceanography, 12, 483-494. http://dx.doi.org/10.1046/j.1365-2419.2003.00244.x

[13] Senina, I., Sibert, J. and Lehodey, P. (2008) Parameter Estimation for Basin-Scale Ecosystem-Linked Population Models of Large Pelagic Predators: Application to Skipjack Tuna. Progress in Oceanography, 78, 319-335. http://dx.doi.org/10.1016/j.pocean.2008.06.003

[14] Corbineau, A., Rouyer, T., Fromentin, J.M., Cazelles, B., Fonteneau, A. and Ménard, F. (2010) Patterns of Variations in Large Pelagic Fish: A Comparative Approach between the Indian and the Atlantic Oceans. Progress in Oceanography, 86, 276-282. http://dx.doi.org/10.1016/j.pocean.2010.04.019

[15] Kumar, P.S., Pillai, G.N. and Manjusha, U. (2014) El Nino Southern Oscillation (ENSO) Impact on Tuna Fisheries in Indian Ocean. SpringerPlus, 31, 591. http://dx.doi.org/10.1186/2193-1801-3-591

[16] Zhu, G., Xu, L., Dai, X. and Liu, W. (2011) Growth and Mortality Rates of Yellowfin Tuna, Thunnus albacares (Perciformes: Scombridae), in the Eastern and Central Pacific Ocean. Zoologia, 28, 199-206. http://dx.doi.org/10.1590/S1984-46702011000200007

[17] Hampton, J. and Fournier, D.A. (2001) A Spatially Disaggregated, Length-Based, Age-Structured Population Model of Yellowfin Tuna (Thunnus albacares) in the Western and Central Pacific Ocean. Marine and Freshwater Research, 52, 
937-963. http://dx.doi.org/10.1071/MF01049

[18] Zurr, A.F., Leno, E.N. and Elphick, C.S. (2010) A Protocol for Data Exploration to Avoid Common Statistical Problems. Methods in Ecology and Evolution, 1, 3-14. http://dx.doi.org/10.1111/j.2041-210X.2009.00001.x

[19] Dickey, D.A. and Fuller, W.A. (1979) Distribution of the Estimators for Autoregressive Time Series with a Unit Root. Journal of the American Statistical Association, 74, 427-431.

[20] MacKinnon, J.G. (1996) Numerical Distribution Functions for Unit Root and Cointegration Tests. Journal of Applied Econometrics, 11, 601-618. http://dx.doi.org/10.1002/(SICI)1099-1255(199611)11:6<601::AID-JAE417>3.0.CO;2-T

[21] Kwiatkowski, D., Phillips, P.C.B., Schmidt, P. and Shin, Y. (1992) Testing the Null Hypothesis of Stationarity against the Alternative of a Unit Root. Journal of Econometrics, 54, 159-178. http://dx.doi.org/10.1016/0304-4076(92)90104-Y

[22] Myers, R.H., Montgomery, D.C. and Anderson-Cook, C.M. (2009) Response Surface Methodology: Process and Product Optimization Using Designed Experiments. John Wiley and Sons, Hoboken.

[23] Buchanan, R.L. and Phillips, J.G. (1990) Response Surface Model for Predicting the Effects of Temperature, pH, Sodium Chloride Content, Sodium Nitrate Concentration and Atmosphere on the Growth of Listeria monocytogenes. Journal of Food Protection, 53, 370-381.

[24] Bezerra, M.A., Santelli, R.E., Oliveira, E.P., Villar, L.S. and Escaleira, L.A. (2008) Response Surface Mothodology as a Tool for Optimization in Analytical Chemistry. Talanta, 76, 965-977. http://dx.doi.org/10.1016/j.talanta.2008.05.019

[25] Box, G.E. and Behnken, D.W. (1960) Some New Three Level Designs for the Study of Quantitative Variables. Technometrics, 2, 455-475. http://dx.doi.org/10.1080/00401706.1960.10489912

[26] Fox, J. (2008) Applied Regression Analysis and Generalized Linear Models. 2nd Edition, Sage Publications, Thousand Oaks.

[27] Akaike, H. (1981) Likelihood of a Model and Information Criteria. Journal of Econometrics, 16, 3-14. http://dx.doi.org/10.1016/0304-4076(81)90071-3

[28] R Core Team (2014) R: A Language and Environment for Statistical Computing. R Foundation for Statistical Computing, Vienna. http://www.R-project.org/

[29] Trenberth, K.E. (1984) Signal versus Noise in the Southern Oscillation. Monthly Weather Review, 112, 326-332. http://dx.doi.org/10.1175/1520-0493(1984)112<0326:SVNITS>2.0.CO;2

[30] Graham, B.S., Grubbs, D., Holland, K. and Popp, B.N. (2007) A Rapid Ontogenetic Shift in the Diet of Juvenile Yellowfin Tuna from Hawaii. Marine Biology, 150, 647-658. http://dx.doi.org/10.1007/s00227-006-0360-y

[31] Maldeniya, R. (1996) Food Consumption of Yellowfin Tuna, Thunnus albacares, in Sri Lankan Waters. Environmental Biology of Fishes, 47, 101-107. http://dx.doi.org/10.1007/BF00002384

[32] Kuhnert, P.M., Duffy, L.M., Young, J.W. and Olson, R.J. (2012) Predicting Fish Diet Composition Using a Bagged Classification Tree Approach: A Case Study using Yellowfin Tuna (Thunnus albacares). Marine Biology, 159, 87-100. http://dx.doi.org/10.1007/s00227-011-1792-6

[33] Singh, A.A., Sakuramoto, K. and Suzuki, N. (2014) Model for Stock-Recruitment Dynamics of the Peruvian Anchoveta (Eugraulis ringens) off Peru. Agricultural Sciences, 5, 140-151. http://dx.doi.org/10.4236/as.2014.52017

[34] Ho, D.J., Siti, M.D., Jafar-Sidik, M. and Aung, T. (2013) Influence of Weather Condition on Pelagic Fish Landings in Kota Kinabalu, Sabah, Malaysia. Journal of Tropical Biology and Conservation, 10, 11-21. https://www.ums.edu.my/ibtp/images/publication/02-siti\%20maryam.pdf

[35] Picaut, J., Ioualalen, M., Menkes, C., Delcroix, T. and McPhaden, M.J. (1996) Mechanism of the Zonal Displacements of the Pacific Warm Pool: Implications for ENSO. Science, 29, 1486-1489. http://dx.doi.org/10.1126/science.274.5292.1486

[36] Sudre, J., Maes, C. and Garçon, V. (2013) On the Global Estimates of Geostrophic and Ekman Surface Currents. Limnology and Oceanography: Fluids and Environments, 3, 1-20. http://dx.doi.org/10.1215/21573689-2071927

[37] Hansen, J., Sato, M., Ruedy, R., Lo, K., Lea, D.W. and Medina-Elizade, M. (2006) Global Temperature Change. Proceedings of the National Academy of Sciences of the United States of America, 103, 14288-14293. http://dx.doi.org/10.1073/pnas.0606291103

[38] Miyake, M.P., Miyabe, N. and Nakano, H. (2004) Historical Trends of Tuna Catches in the World. FAO Fisheries Technical Paper, No. 467, FAO, Rome.

[39] Miller, K.A. (2007) Climate Variability and Tropical Tuna: Management Challenges for Highly Migratory Fish Stocks. Marine Policy, 31, 56-70. http://dx.doi.org/10.1016/j.marpol.2006.05.006

[40] Sharp, G.D. (1992) Climate Change, the Indian Ocean Fishery, and Empiricism. In: Glantz, M.H., Ed., Climate Variability, Climate Change and Fisheries, Cambridge University Press, Cambridge, 377-416. 
http://dx.doi.org/10.1017/CBO9780511565625.016

[41] Stéquert, B. and Marsac, F. (1989) Tropical Tuna-Surface Fisheries in the Indian Ocean. FAO Fisheries Technical Paper, No. 282, FAO, Rome.

[42] Grol, M.G.G., Nagelkerken, I., Rypel, A.L. and Layman, C.A. (2011) Simple Ecological Trade-Offs Give Rise to Emer One Hit Wondergent Cross-Ecosystem Distributions of a Coral Reef Fish. Oecologia, 165, 79-88. http://dx.doi.org/10.1007/s00442-010-1833-8 